(and not between the parents of the twins) is important for the manifestation of $\mathrm{DZ}$ twinning.

Prof. Aldur W. Eriksson, Department of Human Genetics, van der Boechorststraat 7, Amsterdam, The Netherlands

TWINNING FREQUENCIES

IN BADEN-WURTTEMBERG ACCORDING TO PARENTAL AGE AND BIRTH ORDER

\author{
Comparison between $1955-59$ \\ and $1968-72$
}

PETER PROPPING, JENS KRUGGER

Department of Human Genetics, University of Heidelberg, German Federal Republic

Since the middle of the fifties, the frequency of twinning in the German Federal Republic is declining. In $195^{\circ}$ every 83rd confinement had resulted in a twin birth, whereas in 1970 a twinning rate of $1: 102$ could be observed. This is mainly due to a decline of the $\mathrm{DZ}$ twinning rate, calculated by Weinberg's differential method. Unfortunately, the official statistical publications of Germany only give the absolute figures of the three types of twins without classifying by maternal age.

We had the chance to get the original data of all twin births of Baden-Württemberg (Southwest Germany, 9 million inhabitants) from 1955 to 1972 . At the moment, the analysis of these data is still going on; the comparison of two 5-year-periods (1955-59 and 1968-72) shows the following results:

1. Obviously, the decline of the $\mathrm{DZ}$ twinning rate cannot be explained by a maternal age effect; in all maternal age groups $\mathrm{DZ}$ twinning is less frequent in $1968-72$ than in $1955-59$.

2. There seems to be no obvious change in $\mathrm{DZ}$ twinning when the proportions of the
DZs in all twins are compared for the two periods in the same parity classes.

Therefore the decline of $\mathrm{DZ}$ twinning rates in the German Federal Republic must have other reasons; possible explanations will be discussed.

Dr. Peter Propping, Department of Human Genetics, im Neuenheimer Feld 328, D-69 Heidelberg, German Federal Republic

\section{VARIATIONS OF TWINNING FREQUENGIES IN ITALY IN THE PAST TWENTY YEARS}

\section{M.T. ADAMOLI-LUN, L. GIACCI, E. CONTI}

The Gregor Mendel Institute of Medical Genetics and Twin Research, Rome, Italy

In the past years, in Italy as well as in other countries, the frequency of twin births has undergone a remarkable reduction. At the same time, the ratio at birth between same-sexed and opposite-sexed twin pairs has also been modified. That is to say, according to the classic theories of twin studies, the ratio between $M Z$ and $D Z$ twin births has been modified.

The interdependence between variation of frequency of twin births and variation of the $\mathrm{MZ}: \mathrm{DZ}$ ratio has been analysed, the reduction in time of the number of children born to mothers in advanced fertile age being considered as the possible origin of the reduction of twinning and of $\mathrm{DZ}$ twinning.

The reduced number of children born to mothers aged over 35 appears to only partly account for the observed variability. Socioeconomic conditions in the different regions of Italy are then taken into account, and, finally, the genetic structure of the various populations, as given by consanguinity, is considered.

Dott.ssa M.T. Adamoli-Lun, Istituto Mendel, Piazza Galeno 5, oor6r Roma, Italy 